\title{
Geological time, biological events and the learning transfer problem
}

\author{
Claudia C. Johnson ${ }^{1}$, Joan Middendorf ${ }^{2}$, George Rehrey ${ }^{3}$, Mehmet M. Dalkilic ${ }^{4}$, and Keely \\ Cassidy $^{5}$
}

\begin{abstract}
Comprehension of geologic time does not come easily, especially for students who are studying the earth sciences for the first time. This project investigated the potential success of two teaching interventions that were designed to help non-science majors enrolled in an introductory geology class gain a richer conceptual understanding of the geologic time scale. Our research centered on the results of those interventions since we hypothesized that students who correctly answered exam questions on relative geologic time early in the semester would be able to respond with equal facility to exam questions at the end of the semester that asked them to apply relative geologic time to associated biologic events.

The instructor of the course began this study by using the Decoding the Disciplines model (Pace \& Middendorf, 1998). During the first step of the model, the instructor identified the place where a majority of students in previous classes had the greatest difficulty; that is, in addressing the relative geologic time scale. Next, the instructor articulated the mental moves an expert geologist makes when solving problems using the geological time scale. During lecture the instructor modeled those very same mental tasks for students. Students were then given the opportunity to practice those mental tasks by creating their own personal timeline. Later in the course students completed the second intervention, a categorization grid that also functioned as a classroom assessment of their learning. Students were given exams after both interventions were completed.

Results from the first and second interventions indicated that students were able to understand the conceptual framework of the relative geological time scale. On an exam administered after both interventions were completed, $66 \%$ of the students answered correctly the questions about relative geologic time, an indication that they had gained conceptual knowledge of the subject. In contrast, only 36\% of students answered correctly the exam questions at the end of the semester that focused on relative geologic time with associated biologic events. Pearson Chi-Square tests with $P<0.05$ were used to test our hypothesis. Statistically significant results at $P=0.00$ were attained for all tests, indicating the hypothesis can be rejected.
\end{abstract}

We conclude that a second, more prevalent, underlying problem exists for non-science majors, one that Thorndike and Woodworth (1901), Byrnes (1996), Bransford, Brown, and Cocking (2000) and Bransford and Schwartz (2001) describe as the learning transfer problem. Similar problems have been discussed

\footnotetext{
${ }^{1}$ Department of Geological Sciences, Indiana University, 812-855-0646, claudia@indiana.edu;

${ }^{2}$ Center for Innovative Teaching and Learning, Indiana University, 812-855-9023, middendo@indiana.edu

${ }^{3}$ Scholarship of Teaching and Learning Program, Center for Innovative Teaching and Learning, Indiana University, 812-8564231,grehrey@indiana.edu

${ }^{4}$ School of Informatics/Center for Genomics and Bioinformatics, Indiana University, 812-855-3010, dalkilic@indiana.edu

${ }^{5}$ Scholarship of Teaching and Learning Program, Center for Innovative Teaching and Learning, Indiana University, 812-856-

4231, kmcassid@indiana.edu
} 
as a knowledge transfer problem (Graham et al., 2006). Learning transfer is problematic for students using the geological time scale and calls for additional classroom interventions - interventions designed and scaffolded to provide students the opportunity to practice the set of difficult mental moves required to apply biological events to the relative geological timeline.

Keywords: decoding the disciplines, teaching education

\section{Introduction}

Dating of the Earth, and subsequent development of the geologic time scale, have been fundamental to furthering our understanding of the origins of Earth and of the evolution of life. As early as the 1600's, naturalists and scientists endeavored to assign relative ages to Earth's sedimentary layers, and to its mineral and fossil content. Through the 1800's and by the early 1900's, major breakthroughs in field observations and laboratory experiments allowed for widespread establishment and acceptance of methodologies to date Earth's processes and products. These methodologies now center on relative time - a comparative relationship of older and younger events such as deposition of layers of rocks or age of fossils, and absolute time - a numerical expression of ages established from comparison between the observed abundance of a radioactive isotope and its decay products using known decay rates. Relative and absolute time merge to produce the conventional geologic time scale.

The concept of dating the Earth is so fundamental that the Benchmarks for Science Literacy, in an aim to increase adult literacy about the sciences, proposed that knowledge about the changing conceptualization of the age of the Earth be taught in grades 9-12 (American Association for the Advancement of Science, 2009). AAAS Benchmarks for Science Literacy focus on broad themes of "Extending Time" and "Moving Continents" that pair well with "Evolution of Life" themes. As examples, "Moving Continents" places plate tectonics into an evolving earth perspective, and the "Evolution of Life" theme focuses on evolutionary change over geologic time (for grades $6-8$ ), and the mechanisms of change for older students (grades 912). AAAS recommendations focus on this foundational knowledge about the evolution of Earth and life as the way to better prepare students for further exploration in college-level courses.

The teaching and student learning of evolutionary concepts of Earth and life are arguably an essential component of a general college education. However, student difficulty with understanding geologic time is established in the literature (Trend, 1998; Zen, 2001; Cheek, 2012; Cately \& Novak, 2009; DeLaughter \& Stein, 1998; Dodick \& Orion, 2003), and methods to enhance learning have been investigated (Zhu et al., 2012; Pyle, 2007; Richardson, 2000; Hemler \& Repine, 2002; Nieto-Obregon, 2000; Ritger \& Cummins, 1991). In essence, researchers reported that students lack the conceptual framework that allows them to make sense of the immense time scale of geologic time (Catley \& Novick, 2009). Geologic time has been described as a threshold concept (Cheek, 2010; Meyer \& Land, 2006) - a concept difficult to grasp, fundamental to the grounding in a given discipline and essential for the student to understand before moving on to more difficult mental tasks.

Despite the numerous research publications on the subject of geologic time in the education literature, research on student learning of the geologic time scale remains important because students from disciplines as diverse as the social sciences, humanities and arts enroll in undergraduate geological sciences courses each semester. To these non-geology major students,

Journal of the Scholarship of Teaching and Learning, Vol. 14, No. 4, October 2014. 
instructors provide an education about Earth's processes - whether the course for undergraduate students has a focus on historical geology, physical geology, or environmental geology, or any such course that allows for the students to gain a perspective on the temporal sequence of unfolding of Earth's events or processes. A full comprehension of geologic time allows students to view the Earth's integrated biologic, chemical and physical events in their temporal sequence. We assert that mastery of the concept of geologic time, inclusive of relative and absolute geologic time, is not a goal for undergraduate non-science majors, but that a fundamental application of relative geologic time and associated events should be considered an achievable learning outcome for students enrolled in a non-majors geological sciences course.

Our research objective was to investigate if students in a non-science majors undergraduate course in a large Midwestern university are learning the concept of the relative geologic time scale, and are able to apply biologic events that occurred in Earth's history to the relative geologic time scale at the end of the semester with a probability that is better than chance alone. Results from pre- and post-pedagogical intervention activities pertaining to student learning and understanding of geologic time administered in the undergraduate classroom in the 2012, 2011 and 2010 fall semesters comprise our database. In each semester, approximately twothirds of the classroom student population that participated in this study were lower division freshman and sophomores and one-third was upper division students.

The course Dinosaurs and Their Relatives in a geosciences department in a large, statesupported Midwestern university in the U.S. was targeted for our research because this course focused almost entirely on relative geologic time and biologic events, instead of geologic time and chemical, physical and biological events more typical for an undergraduate non-science majors geology course. Our focused research objective was designed to analyze student learning of relative geologic time and terms early in the semester, and of relative geologic time with associated biologic events by the close of the semester. Our research hypothesis was this: if students learn relative geologic time early in the semester, then they will learn relative geologic time with associated biologic events by the end of the semester with equal facility. Although our intent was to quantify and analyze student learning of the threshold concept of relative geologic time, our research results uncovered another significant problem but one quite common among the STEM disciplines -learning transfer within a given course. Thus, our disciplinary and focused research on geologic time and associated biologic events directed us to identify the larger conceptual issue of learning transfer that is occurring in the classroom.

\section{Methods}

To apprehend the complexities of geologic time, lessons and classroom learning activities were designed specifically to help students gain an understanding of the geologic time scale. At the outset of the semester, an exercise was initiated by asking students to draw a vertical line that represents time, from oldest time at the bottom of the page to youngest at the top, and to insert, beginning with their birth, 3-4 significant events that occurred in their lives (see Figure 1). Upon completion, each student constructed a time line similar to the geologic time line, with a list of relative events that occurred at single points in time. A corresponding geologic time summary was given during the class (see Figure 2). 


\section{STUDENT PRACTICE}

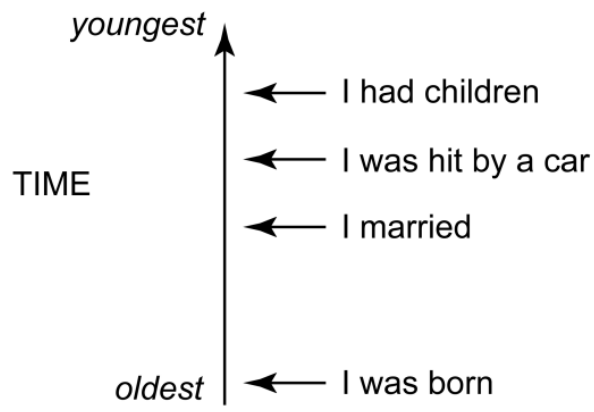

Figure 1. An example of a simplified time scale that can be constructed by students in the classroom for the purpose of illustrating the development of a geologic time line, with older to younger time punctuated by important events.

\section{STUDENT PRACTICE}

\begin{tabular}{l|l} 
HUMAN SUMMARY & GEOLOGIC SUMMARY \\
\cline { 2 - 2 } $\begin{array}{l}\text { - some events are older than others } \\
\text { - some events depend on those that } \\
\text { precede them }\end{array}$ & $\begin{array}{l}\text { e.g. I was born with certain features } \\
\text { (hair color, eye color); these were } \\
\text { passed on to my children }\end{array}$ \\
$\begin{array}{l}\text { - some events just happened } \\
\text { e.g. hit by a car (don't know how } \\
\text { they relate to anything, if they ever will) }\end{array}$ & $\begin{array}{l}\text { - we're still investigating many geologic } \\
\text { occurrences }\end{array}$ \\
- time marched on through all your events & $\begin{array}{l}\text { geologic time is continuous and } \\
\text { punctuated by important biological, } \\
\text { physical, and chemical events in } \\
\text { Earth's history }\end{array}$ \\
&
\end{tabular}

Figure 2. Students learn by association to their own personal experiences, in this case, to events that occurred in their lives. A student-developed time line could be linked to lessons on geologic concepts at this point and/or later in the semester. The instructor can then use the individual student summaries for comparison to geologic topics later in the semester as a means of introducing more complex information; i.e., evolution.

Through a one-hour lesson created by using the Decoding the Disciplines method, an instructor modeled the use of the relative geologic time scale to students so that they could link relative geologic time to the readings and classroom lectures throughout the semester. The instructor began the lesson by breaking down the standard textbook example of the geologic time scale columns from the largest to smallest divisions, explaining the terms and numbers, and identifying clearly the position of the present day on the chart. The division boundaries were identified, and erathem boundaries were discussed in relation to major extinction events. A 
simplified set of examples followed; i.e., the origin of the dinosaurs was marked at a particular level on the geologic time scale, as was the extinction of the dinosaurs, but it was explained that the dinosaurs lived continuously through many millions of years between the origination and extinction event (see Figure 3). Although a particular event was identified on the simplified time scale as a single point in time by the horizontal arrow (i.e., origin or extinction), the duration of the event may have occurred over many hundreds of thousands or perhaps even millions of years. The relatively shorter duration of geologic time that marked a specific geologic event such as the extinction of the dinosaurs was contrasted with the relatively longer time associated with the duration of the Paleozoic, Mesozoic or Cenozoic eras. It was explained further that time continued through the evolutionary event and through the extinction event and persists to today, much as time will continue tomorrow and will have been punctuated by events that occurred in the students' lives today (see Figure 4). Further examples relating geologic time to the human experience were provided for the students to reinforce the concepts. Familiar topics such as the origin of mammals and the origin of fish were identified on the time scale (see Figure 5). In a similar manner, the age of the Earth in billions of years, the duration of dinosaurs in millions of years and the age of our family members in hundreds and tens of years were provided in one lesson period and reinforced as themes throughout the course.

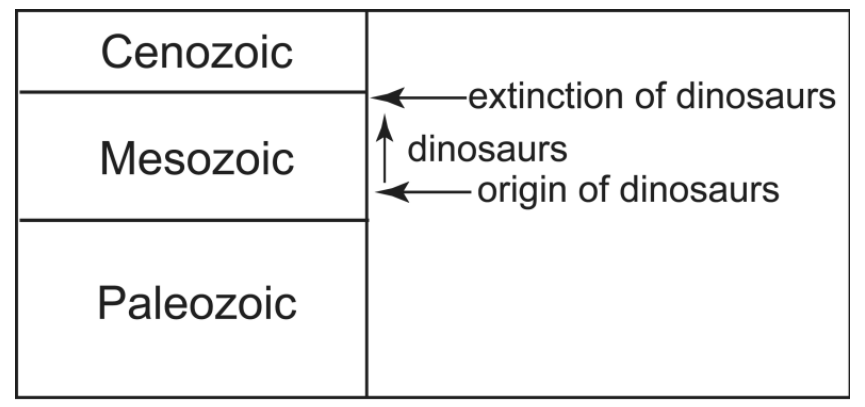

Figure 3. The origin, temporal duration and extinction of the dinosaurs during the Mesozoic are the focal points for the students' attention in this abbreviated geologic time scale. The objective of the lesson is to include geologic information to assist students in practicing terms and concepts related to understanding relative geologic time.

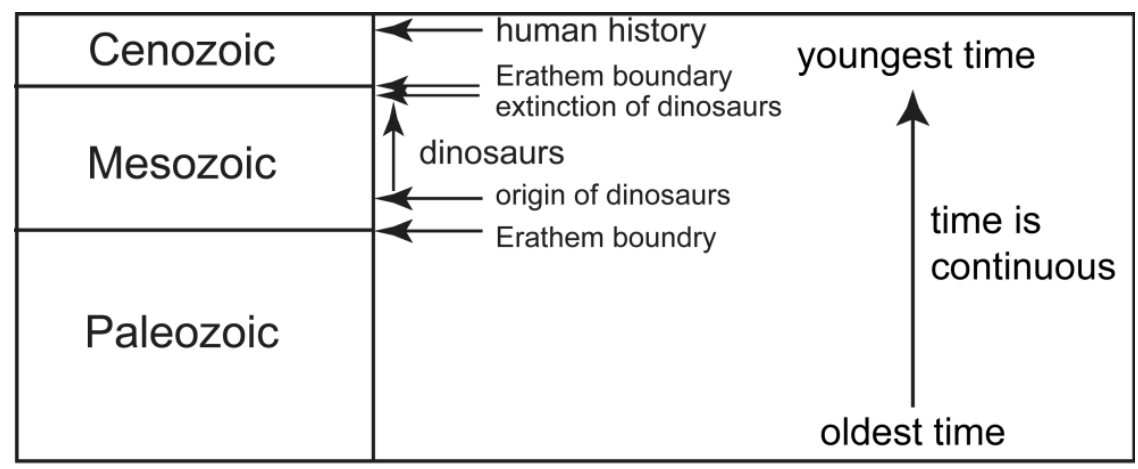

Figure 4. A portion of the relative geologic time scale with oldest and youngest time, and a very approximate position of the beginning of human history in the latest Cenozoic identified on the column. A convention in geology is to use horizontal arrows to point to times during which geologic events occurred in Earth's history. Diagram provides a summary of the lesson that time 
is continuous and is punctuated by relatively older events (origin of the dinosaurs) and relatively younger events (extinction of the dinosaurs), as well as extinctions at erathem boundaries, with focus on the Mesozoic.

\begin{tabular}{|c|c|c|}
\hline Cenozoic Era & & \\
\hline \multirow{3}{*}{ Mesozoic Era } & Cretaceous & $\begin{array}{l}\text { extinction of dinosaurs } \\
\text { origin of angiosperms }\end{array}$ \\
\hline & Jurassic & origin of birds \\
\hline & Triassic & $\begin{array}{l}\text { (origin of birds) } \\
\text { origin of dinosaurs } \\
\text { origin of mammals }\end{array}$ \\
\hline Paleozoic Era & & $\begin{array}{l}\text { origin of gymnosperms } \\
\text { origin of seedless vascular plants } \\
\text { origin of fish }\end{array}$ \\
\hline
\end{tabular}

Figure 5. The relative geologic time scale associating the terms for relative geologic time to events that may be familiar to students, such as the origin of fish, origin of mammals, etc.

Another aspect of geologic time conveyed to students was an understanding that some events were of relatively longer versus shorter duration. This is a complicated concept because it requires students to hold billions or millions versus millions or hundreds of thousands of years in their heads. Specific classroom assessments (Angelo \& Cross, 1993) were used to gauge student learning of comparative durations of geologic events and were classified according to the hierarchical learning scheme described by Bloom (1964). Lower level thinking requires students to memorize and comprehend knowledge, while higher learning levels such as analysis, application, synthesis and evaluation require more complex thinking. In our research the Categorizing Grid, "a paper and pencil equivalent of sorting objects in a warehouse and putting like ones together in the right bin," (Angelo \& Cross, 1993, p. 160) served to evaluate student 
comprehension of geologic time in the class. The Categorizing Grid required students to sort geologic events of relatively longer duration; e.g., the Mesozoic Era, from events that occurred over a relatively shorter period of geologic time; e.g., origin or extinction of dinosaur groups. The latter events are portrayed commonly on geologic time scales by horizontal arrows pointing to a single point in geologic time (see Figures 3 and 4), although the understanding of the geologist is that the arrow may represent tens, hundreds of thousands or millions of years. Duration of geologic time and a single point in geologic time were the category titles under which the following list of terms or phrases were to be sorted by the students in the Grid (see Figure 6):
- $\quad$ Paleozoic Era
- $\quad$ Mesozoic Era
- $\quad$ Cenozoic Era
- $\quad$ Erathem boundary
- $\quad$ Origin of mammals
- $\quad$ Number of years dinosaurs roamed the Earth
- $\quad$ Origin of the dinosaurs
- $\quad$ Extinction of the dinosaurs
- $\quad$ Number of years mammals existed on Earth
- $\quad$ Evolutionary change that is gradual
- $\quad$ Evolutionary change that is punctuated

All terms and phrases were discussed in previous class lessons and prior to conducting the assessment. The Categorizing Grid assessed student understanding of the relative duration of significant geologic terms and events at the comprehension level (Bloom, 1964). The Categorizing Grid constituted the second of the interventions discussed in this research study. The Categorizing Grid was administered the second week of each of the three semesters for which data were collected for this study.

\section{Categorizing Grid}

\begin{tabular}{l|l}
\multicolumn{1}{c}{ Duration of geologic time } & \multicolumn{1}{c}{ A single point in geologic time } \\
\hline $\begin{array}{l}\text { Paleozoic Era } \\
\text { Mesozoic Era }\end{array}$ & $\begin{array}{l}\text { erathem boundary } \\
\text { origin of mammals } \\
\text { number of years dinosaurs roamed the Earth }\end{array}$ \\
$\begin{array}{l}\text { number of years mammals existed on the Earth } \\
\text { ovolutionary change of dinosaurs }\end{array}$ \\
Cenozoic Era
\end{tabular}

Figure 6. An exercise labeled a Categorizing Grid by Angelo and Cross (1993) serves as our example that requires students to utilize knowledge and comprehension of geologic information before placing terms and phrases under the correct heading. 
One third of the way through each semester, Exam 1 was administered to all students in the course and the following True/False questions were evaluated.

Exam 1. Question \#21. The Cenozoic is older than the Paleozoic.

Exam 1. Question \#28. The Paleozoic is younger than the Mesozoic.

Students were instructed in writing on the exam to fill in True or False to complete each statement correctly. Exam 1 was administered during the sixth week of the semester. All exams were collected and corrected soon after students took the exam. Exam 1 was not returned to the students. Correct responses are: The Cenozoic is older than the Paleozoic. False. The Paleozoic is younger than the Mesozoic. False.

The semester course focused on dinosaur evolution, phylogeny, morphology, paleoecology, biogeography, and extinction. Format consisted of classroom presentations by lecture inclusive of images and DVDs of dinosaurs, in-lecture written activities on the Triassic, Jurassic and Cretaceous periods and their association with the major dinosaur groups theropods, sauropods, anklyosaurs, ceratopsians, ornithopods, stegosaurs, and pachycephalosaurians. Students were required to memorize the Paleozoic, Mesozoic and Cenozoic, Triassic, Jurassic and Cretaceous periods, and the seven names of dinosaur groups. The three periods of the Mesozoic and dinosaur names were reinforced with in-lecture written exercises and DVD viewings numerous times during the 16-week semester.

Exam 3 was administered at the end of each semester. Similar to the previous exam, students were instructed in writing on the exam to fill in True or False to complete each statement correctly. All exams were collected and corrected soon after students took the exam, and the exam was not returned to the students. The two questions were taken from the textbook and evaluated for this second phase of the post-intervention research.

Question \#22. Sauropods were much less successful after the Jurassic, but did survive until the end of the Cretaceous. Correct response is True.

Question \#33. The middle and Late Cretaceous dinosaurs were mostly hadrosaurs, ceratopsians, anklyosuars and giant sauropods. The correct response is False.

\section{Results and Discussion}

Student responses to the first intervention activity (the time line punctuated from oldest to youngest with personal events important to students' lives) indicated that students clearly comprehended the construct of the geologic time line and were able to apply personal experiences in the correct order, from older to younger personal events. In the exercise, $97 \%$ (254/263) of the student time lines were constructed correctly. Correct student responses were those that gave the oldest information at the bottom of the time line and progressively younger events upward, with the youngest or most recent event at the top of the page. Incorrect time lines were those that associated a student's birth with the youngest time at the top of the page, thereby producing the reverse of the geologic time scale. At this earliest part of the semester, $97 \%$ of students understood the relative ordering of terms as per the geologic time line, with oldest events on the bottom of the page and youngest at the top.

Incorrect student responses to the Categorizing Grid exercise, inclusive of placing one or more terms or phrases into the incorrect category and/or exclusion of terms, phrases, and/or category headings, indicated the difficulties students had with understanding geologic time when geologic terminology was paired with relative durations of geologic time early in the semester.

Journal of the Scholarship of Teaching and Learning, Vol. 14, No. 4, October 2014. 
Student responses to Exam 1 questions on relative geologic time were fairly consistent across the three semesters - Fall 2012, 2011, 2010. Results averaged for the three years revealed $66 \%$ of students answered the two Exam 1 questions pertaining to relative geologic time correctly (Year 2012: 67\%, Year 2011: 70\%, Year 2010: 62\%; Average 66\%; Appendices 1, 2, 3). Questions were posed as True/False so each student had a 50/50 opportunity of attaining the correct answer for each question by chance alone. Our results of $66 \%$ average correct responses are better than chance alone and indicate student knowledge of correct responses to questions pertaining to relative geologic time 6 weeks after the semester began.

Student responses to two questions pertaining to relative geologic time with a biologic component on Exam 3 were also fairly consistent across three years. However, results averaged for the three-year duration of the study $(2012,2011,2010)$ revealed only $36 \%$ of students answered both questions pertaining to relative geologic time with a biologic component correctly on Exam 3 (Year 2012: 35\%; Year 2011: 44\%; Year 2010: 31\%; Average 36\%). Questions were posed as True/False with the expectation that a student had a 50/50 chance of arriving at the correct answer for each question by chance alone.

The distribution of correct and incorrect student responses to both questions pertaining to relative geologic time on Exam 1 and to both questions pertaining to relative geologic time with a biologic component on Exam 3 were examined for statistical significance. The hypothesis of no significant difference between the $\mathrm{T} / \mathrm{F}$ responses from relative geologic time questions on Exam 1 and relative geologic time with a biologic component questions on Exam 3 was tested at $\mathrm{P}<0.05$. Statistically significant results were obtained for all analyses, inclusive of individual years and the three years combined data. Chi-Square tests for individual years yielded $\mathrm{P}=0.00$ (Year 2012: $\mathrm{P}=0.00$; Year 2011: $\mathrm{P}=0.00$; Year 2010: $\mathrm{P}=0.00$ ), and the same for three years combined data $(\mathrm{P}=0.00)$. An examination of a subset of the data - only one question from Exam 1 and only one question from Exam 3 for all years (Exam 1 Q21 (2010-2012) (86\% correct) / Exam 3 Q22 (2010-2012) (46\% correct) also yielded statistically significant results at $\mathrm{P}=0.00$. Collectively, these results indicate there is a statistically significant difference between student responses to relative geologic time questions given early in the semester (Exam 1) and to relative geologic time with a biologic component questions given at the end of the semester (Exam 3). In other words, students did better than chance on relative geologic time questions early in the semester, but did poorer than chance on relate relative geologic time and biologic components at the end of the semester.

We examined further the data from Exam 3 questions, both directed at relative time with a biologic component, to determine if there was a statistically significant difference between the responses. These additional investigations were conducted because one question required more knowledge of both relative geologic time and dinosaur groups than the other. Again, each question was $\mathrm{T} / \mathrm{F}$ so the probability of a student attaining the correct response was 50/50. The hypothesis of no significant difference between the $\mathrm{T} / \mathrm{F}$ responses from these two questions on Exam 3 was tested at $\mathrm{P}<0.05$. Chi-Square tests yielded $\mathrm{P}=0.00$ for all tests. Results indicate a statistically significant difference between student responses to the two questions on relative time with a biologic component.

In total, three analyses of student learning of relative geologic time were prepared from three consecutive years of student responses to True/False questions. First analysis pertained to knowledge of relative geologic time on Exam 1, second to testing knowledge and comprehension of relative geologic time with a biologic component on Exam 3, and third pertained to testing knowledge and comprehension of relative geologic time with a biologic component - with one 
question requiring comparatively more knowledge of both relative geologic time and dinosaur groups than the other.

Overall, results from our research indicate that $97 \%$ of the students were able to construct geologic-like time lines that relate to their own personal experience at the outset of the semesters, and $3 \%$ of the population tested needed additional instruction. A lesson on geologic time using the Decoding the Disciplines methodology demonstrated use of the relative geologic time scale and enabled students to apply information on relative geologic time through the semester's lectures and activities. Further testing with the addition of geologic terms in a categorizing grid administered in the second week of the semester allowed students to practice the task correctly. Thus, early in the semester, knowledge and comprehension skills regarding these particular geologic terms and the concept of relative geologic time were emphasized for students in the class. Moreover, memorization and comprehension of the relative geologic time scale eras had occurred for the majority of the students at the completion of Exam 1, as $66 \%$ of the students knew the relative positions of the Paleozoic, Mesozoic and Cenozoic geologic eras. Exam 3 results, however, indicated that only $36 \%$ of students answered the relative placement of geologic time and biologic events correctly. The bottleneck on relative geologic time and associated biologic events remained firmly in place for $64 \%$ of the students at the end of the semester and one assumes that these students completed the class with incomplete knowledge of the relative geologic time scale for the Mesozoic and biological events pertaining to dinosaurs the focus of the semester course. Our numerical analysis shows statistically significant results, and our hypothesis of equal facility of learning geologic time, and geologic time with associated biologic events by the end of the semester, was rejected.

In the case of our entry-level college course, we worked under the assumption that we were building on the principles expounded by the Benchmarks for Science Literacy - the foundational knowledge of dating the Earth and life that students bring to the college classroom. In assessing college level abilities at the end of the semesters' teaching, however, our findings indicate that more intentional interventions must be available to students if we expect them to accomplish the mental moves required to associate geologic time and biological events in the non-science majors undergraduate classroom. Our inquiry into the threshold concept of the geologic time scale thus uncovered a more deeply rooted issue of content knowledge, and the failed expectation of transfer of content knowledge from one level to the next. This is of course more basic than knowledge transfer as defined by Graham et al. (2006). It is, however, more closely related to learning transfer, a concept discussed extensively by Bransford et al (2000). The ability of students to organize information into conceptual frameworks is a key finding in the research on learning transfer (Bransford et al., 2000). In other words, competence in a field of inquiry initiates with factual knowledge, continues with an understanding of the facts in a conceptual framework, and is furthered with an organization of knowledge for retrieval and application (Bransford et al., 2000). These authors claim further that conceptual framing on the part of the student allows for greater learning transfer, and the "ability to plan a task, to notice patterns, to generate reasonable arguments and explanations, and to draw analogies to other problems are all more closely intertwined with factual knowledge than was once believed".

Our overall research results thus indicate that associating geologic time and biologic events remains a bottleneck and requires a paradigm shift. More frequent classroom activities as per Decoding the Disciplines methodology, followed by equally frequent classroom assessments, would allow students to practice the type of mental tasks required to transfer knowledge and comprehension of biological events located within a temporal geologic framework. 
The exercises and exam questions presented in our research did not test for diachronic thinking skills - the ability to represent geologic transformations over time - that would be required for classroom discussions on complex topics such as dinosaur extinction. Cognitive factors that accounted for difficulties students encountered in attempting diachronic thinking were identified by Dodick and Orion (2003a). These researchers found that students could think in terms of tens, hundreds, and even thousands of years, but time became an abstraction when events that occurred millions or billions of years ago were presented; the enormous time scale was beyond students' comprehension. Researchers also observed that students tended to cluster strata into equal-sized packages and assign equal time to them, "...almost as if they were units on a ruler" (Dodick \& Orion, 2003a, p. 436); in geology, however, the temporal duration of strata is rarely proportional to size. It was further noted that students did know how to use static or inert clues such as fossils and landforms to "visualize the dynamic processes of the past such as sedimentation," (Dodick \& Orion, 2003a, p. 436). While our results show student scores for understanding of relative geologic time at the knowledge and comprehension levels of understanding, we do not address higher-order thinking skills that would be required for nonscience majors to comprehend the complexities and significance of Earth's integrated physical, chemical and biological events - the transformations of geologic time as identified by Dodick and Orion (2003a). In future studies, however, geologic aptitude tests such as those developed by Dodick and Orion (2003b) would be excellent additions to assessment of student learning in the college classroom in introductory geology courses.

In summary, although our research results document difficulty students have with the learning of relative geologic time as related to biologic events in an introductory non-science majors course focusing on dinosaurs, we surmise that our research findings may be extended to more complex introductory geology courses that integrate biological, chemical and physical events within the context of both relative and absolute geologic time. Further, our findings are potentially applicable to fields outside of the geological curriculum. The teaching of evolutionary trees in biology requires a firm foundational understanding of the scaling of time (Meir, Perry, Herron, \& Kingsolver, 2007). The spatial representation of time in an evolutionary tree is similar to the spatial representation of time that we performed in the methods of this study, wherein the older events may be portrayed at the bottom of the diagram and the younger events at the top. The medical field places great importance on timescales, as seen in disease processes and prognoses studied in epidemiology. There are various scales (e.g., date of diagnosis, date of recurrence, patient age) being used in epidemiological follow-up studies (Chubak, Yu, Buist, Wirtz, \& Boudreau, 2013) that can impact the treatment plan of individuals as well as the statistical analysis of incident rates. Future healthcare professionals must be aware of and be able to navigate these various timescales. In sociological and philosophical studies, Lemke (2000; 2009) states that social-ecological systems "with all their many sublevels of organization" require an understanding of the lower organizational levels before trying to study the higher levels. This philosophy agrees with our research methods, in which students had to first understand the direction of geologic time before placing related biologic events on the time scale.

In essence, scaling issues are beyond students' common practices in numerous academic disciplines. Because of this shared experience, we suggest an intentional intervention to enhance student-learning that can be utilized across disciplines. This intervention is a hybrid model based upon our collective understanding and experiences of bottlenecks, threshold concepts and disciplinary ways of knowing, and is grounded in research recorded in the Decoding the 
Disciplines model of Pace and Middendorf (2004). To begin the intervention, a bottleneck or threshold concept is introduced early in the semester, reinforced through student practice, and expanded upon through the semester with levels of increasing complexity. Modeling through metaphors is a crucial part of helping students learn a complex skill (Jones et al, 20100).

- Identify a bottleneck or threshold concept.

- Decode for the students the instructor's mental processes by breaking down the threshold concept into sub-components. (For details of the decoding process, see Pace \& Middendorf, 2004).

- Model an example with use of metaphors relevant to the students.

- Present a student exercise and include challenging components that relate the threshold concept to the human experience.

- Assess student-learning from the exercise and address immediately misconceptions and errors. Reinforce the correct concept.

- Build on the threshold concept incrementally through the semester by modeling examples that construct the concept with increasing complexity.

- Continue to present students with practice exercises that emphasize the mental skills involved in developing the integrated complexity of the threshold concept.

- Assess student-learning and provide feedback frequently during the process, discuss misconceptions and errors, reinforce the corrections.

Although fostering content knowledge is a teaching goal in STEM education (Bao et al., 2009), clearly this objective was not achieved in our study, as evidenced by the test question results over a three-year study. "Because students ideally need to develop both content knowledge and transferrable reasoning skills, researchers and educators must invest more in the development of a balanced method of education, such as incorporating more inquiry-based learning that targets both goals" (Bao et al., 2009, p. 587). Whereas our primary goal was to better understand how students in a non-majors course apply timescales in a way that may vastly exceed their experience and knowledge, we conclude that further research into transfer of learning in many disciplines remains a fruitful avenue for investigation, especially as pertains to developing methodological approaches to teaching intervention, and assessment of both knowledge and transferable reasoning skills.

\section{Acknowledgements}

We acknowledge the critique and helpful suggestions for improvement of an early version of this manuscript by K. Kearns. We thank Guanru Zhang, Department of Geological Sciences, Indiana University, Bloomington, for assistance with statistical analyses.

\section{References}

American Association for the Advancement of Science. (2009). Benchmarks for science literacy. New York, NY: Oxford University Press. Retrieved from http://project2061.aaas.org/tools/benchol/bolframe.html (Original work published 1993)

Angelo, T., \& Cross K.P. (1993). Classroom assessment techniques: A handbook for college teachers (2 ${ }^{\text {nd }}$ ed.). San Francisco, CA: Jossey-Bass. 
Johnson, C.C., Middendorf, J., Rehrey, G., Dalkilic, M.M., \& Cassidy, K.

Bao, L., Cai, T., Koenig, K., Fang, K., Han, J., Wang, J., Liu, Q., Ding, L., Cui, L., Luo, Y., Wang, Y., Li, L., \& Wu, N. (2009). Learning and scientific reasoning. Science, 323(5914), 586587. doi: $10.1126 /$ science. 1167740

Bloom, B. S. (1964). Taxonomy of educational objectives: The classification of educational goals, by a committee of college and university examiners. New York, NY: Longmans and Green.

Bransford, J.D., Brown, A.L., \& Cocking, R.R. (Eds.). (2000). How people learn: brain, mind, experience, and school. Washington, DC: National Academy Press.

Bransford, J.D., \& Schwartz, D.L. (2001). Rethinking transfer: A simple proposal with multiple implications. Review of Research in Education, 24, 61-100.

Byrnes, J.P. (1996). Cognitive development and learning in instructional contexts. Boston, MA: Allyn and Bacon.

Catley, K. M., \& Novick, L. R. (2009). Digging deep: Exploring college students' knowledge of macroevolutionary time. Journal of Research in Science Teaching, 46(3), 311-332. doi:

$10.1002 /$ tea.20273

Cheek, K. A. (2010). Why is geologic time troublesome knowledge? In R. Land, J.H.F. Meyer, \& Baillie C. (Eds.), Threshold concepts and transformational learning (117-129). Rotterdam, The Netherlands: Sense Publishers.

Cheek, K. A. (2012). Students' understanding of large numbers as a key factor in their understanding of geologic time. International Journal of Science and Mathematics Education, 10(5), 1047-1069. doi: 10.1007/s10763-011-9312-1

Chubak, J., Yu, O., Buist, D.S.M., Wirtz, H.S., \& Boudreau, D.M. (2013). Time scale in followup studies: Considering disease prognosis [Letter to the editor]. Epidemiology, 24(4), 628-629. doi: 10.1097/EDE.0b013e3182961708

DeLaughter, J. E., \& Stein, S. (1998). Preconceptions about earth science among students in an introductory course. EOS, ,79 429-432. doi: 10.1029/98EO00325

Dodick, J., \& Orion, N. (2003a). Cognitive factors affecting student understanding of geological time. Journal of Research in Science Teaching, 40, 415-442. doi: 10.1002/tea.10083

Dodick, J., \& Orion, N. (2003b). Measuring student understanding of geological time. Science Education, 87, 708-731. doi: 10.1002/sce.1057

Graham, I.D., Logan, J., Harrison, M.B., Straus, S.E., Tetroe, J., Caswell, W., \& Robinson, N. (2006). Lost in knowledge translation: Time for a map? The Journal of Continuing Education in the Health Professions, 26, 13-24. doi: 10.1002/chp.47

Journal of the Scholarship of Teaching and Learning, Vol. 14, No. 4, October 2014. 
Johnson, C.C., Middendorf, J., Rehrey, G., Dalkilic, M.M., \& Cassidy, K.

Hemler, D., \& Repine, T. (2002). Reconstructing the geologic timeline. The Science Teacher 69(4), 32-35.

Jones, N. A., Ross, H., Lynam, T., Perez, P., \& Leitch, A. (2011). Mental models: An interdisciplinary synthesis of theory and methods. Ecology and Society, 16(1), 46-46.

Lemke, J.L. (2000). Across the scales of time: Artifacts, activities, and meanings in ecosocial systems. Mind, Culture, and Activity, 7(4), 273-290. doi: 10.1207/S15327884MCA0704_03

Lemke, J.L. (2009). The long and the short of it: Comments on multiple timescale studies of human activity. Journal of the Learning Sciences, 10, 17-26. doi: 10.1207/S15327809JLS10-123

Libarkin, J. C., Kurdziel, J. P., et al. (2007). College student conceptions of geological time and the disconnect between ordering and scale. Journal of Geoscience Education, 55(5), 413-422.

MacKinnon, G. R. (2003). Why models sometimes fail: Eight suggestions to improve science instruction. Journal of College Science Teaching, 32, 430-433.

Meir, E., Perry, J., Herron, J.C., \& Kingsolver, J. (2007). College students' misconceptions about evolutionary trees. The American Biology Teacher, 69(70), 71-76. doi: 10.1662/00027685(2007)69[71:CSMAET]2.0.CO;2

Meyer, J., \& Land, R. (Eds.). (2006). Overcoming barriers to student understanding: Threshold concepts and troublesome knowledge. London and New York, NY: Routledge.

Middendorf, J., \& Pace, D. (2004). Decoding the disciplines: A model for helping students learn disciplinary ways of thinking. In D. Pace \& J. Middendorf (Eds.), Decoding the Disciplines: Helping Students Learn Disciplinary Ways of Thinking: New Directions for Teaching and Learning, No. 98 (1-12). San Francisco, CA: Jossey-Bass.

Nieto-Obregon, J. (2001). Geologic time scales, maps, and the chronoscalimeter. Journal of Geoscience Education, 49(1), 25-29.

Novak, G. M., Patterson, E. T., Gavrin, A. D., \& Christian, W. (1999). Just-in-time teaching: Blending active learning with web technology. Upper Saddle River, NJ: Prentice Hall.

Pace, D., \& Middendorf, J. (Eds.). (2004). Decoding the Disciplines: Helping Students Learn Disciplinary Ways of Thinking: New Directions for Teaching and Learning, No. 98. San Francisco, CA: Jossey-Bass.

Pyle, C. (2007). Teaching the time: Physical geography in four dimensions. Teaching Geography 32(3), 121-123.

Richardson, R. M. (2000). Geologic time (clothes) line. Journal of Geoscience Education, 48, 584. 
Johnson, C.C., Middendorf, J., Rehrey, G., Dalkilic, M.M., \& Cassidy, K.

Ritger, S. D., \& Cummins, R. H. (1991). Using student-created metaphors to comprehend geologic time. Journal of Geological Education, 39, 9-11.

Thorndike, E. L., \& Woodworth, R. S. (1901). The influence of improvement in one mental function upon the efficacy of other functions. Psychological Review, 8, 247-261. doi: $10.1037 / \mathrm{h} 0074898$

Trend, R. D. (1998). An investigation into understanding of geological time among 10- and 11year-old children. International Journal of Science Education, 20, 973-988. doi: $10.1080 / 0950069980200805$

Zen, E. A. (2001). What is deep time and why should anyone care? Journal of Geoscience Education, 49(1), 5-9.

Zhu, C., Rehrey, G., Treadwell, B., \& Johnson, C. (2012). Looking back to move ahead: How students learn deep geological time by predicting future environmental impacts. Journal of College Science Teaching, 41(3), 61-66. 